\title{
Cyclic GMP phosphodiesterase from bovine retina
}

\author{
Evidence for interspecies conservation
}

\author{
Larry J. TAKEMOTO,* Jeffrey HANSEN,* Debora B. FARBER, $\dagger$ Dennis SOUZA $\dagger$ and \\ Dolores J. TAKEMOTO $\ddagger$ \\ ${ }^{*}$ Division of Biology and $\ddagger$ Department of Biochemistry, Kansas State University, Manhattan, KS 66506, \\ U.S.A., and †Jules Stein Eye Institute, University of California, Los Angeles, CA 90024, U.S.A.
}

(Received 25 July 1983/Accepted 31 August 1983)

\begin{abstract}
A light-activated phosphodiesterase (PDE) from retinal rod outer segments (ROS) has been strongly implicated as a possible mediator in the propagation of the visual response. In view of the probable importance of this enzyme in the visual system, a comparison of the PDE proteins from ROS of different evolutionary species was made. Partial purification of the PDE, as measured by enzymic activity, followed by resolution of the protein components on sodium dodecyl sulphate/polyacrylamide-gel electrophoresis, indicated that the major Coomassie Blue-staining species in the ROS of all species studied is a doublet of $84000-88000 \mathrm{Da}$. After radioiodination, this doublet was converted in all but the frog proteins into a single band of $85000 \mathrm{Da}$. Twodimensional tryptic peptide mapping of the radioiodinated peptides indicated that at least six major peptides of the putative PDE have been conserved in all of the species studies. If this protein is indeed associated with PDE activity, such conserved peptides may play an important role in the catalytic and/or regulatory functions of the enzyme.
\end{abstract}

In photoreceptor cells, the levels of cyclic GMP are decreased after light activation of a cyclic GMP PDE (Goridis et al., 1973; Miki et al., 1973; Pober \& Bitensky, 1979). During this phenomenon, 1000-2000 molecules of cyclic GMP are degraded per molecule of bleached rhodopsin (Woodruff et al., 1977). This activation is both fast enough and of sufficient magnitude to play an important role in photoreception. In addition, the loss of this PDE activity in the $r d$ mouse phenotype, which undergoes a genetically determined retinal degeneration, further suggests that this enzyme is involved in photoreceptor responses (Farber \& Lolley, 1976, 1977; Aguirre et al., 1978).

Miki et al. (1975) isolated the ROS PDE from frog retina. Characterization of this preparation by SDS/PAg.e. indicated the presence of two subunits with apparent molecular weights of 110000 and 120000. Coquil et al. (1975) and Baehr et al. (1979) isolated a cyclic GMP PDE from bovine ROSs. The bovine PDE proteins prepared by Baehr $e t$ al. (1979) differ from the frog enzyme in having sub-

Abbreviations used: PDE, phosphodiesterase; ROS, rod outer segment; SDS, sodium dodecyl sulphate; PAg.e., polyacrylamide-gel electrophoresis. units with apparent mol.wts. of 84000 and 88000 .

Studies of the frog ROS demonstrated that light activation of PDE was lost upon elution of this enzyme from the membrane (Miki et al., 1975). These results suggest that the interaction of PDE with other membrane-bound molecules is essential to the light-activation process. These molecules may include rhodopsin and/or a light-activated GTPase, which is probably related to the G-protein (Pober \& Bitensky, 1979) or transducin (Fung et al., 1981) described recently.

In view of the possible importance of the lightactivated PDE system in the visual response, a careful comparison of the PDE proteins from different evolutionary species may be valuable in characterizing those parts of the molecule important in the mechanism of the visual response. In the present paper we describe the results of twodimensional tryptic peptide mapping of the radioiodinated peptides of putative PDEs isolated from the ROS of frog, chicken, cow and dog.

\section{Materials and methods}

Purification of ROS PDES

ROS membranes were isolated by the method of 
Papermaster \& Dreyer (1974) as modified by Baehr et al. (1979). We have found that the $\mathrm{MgCl}_{2}$ free supernatant from the washed ROS membranes contained PDE that was of sufficient purity after gel electrophoresis for use in peptide mapping studies.

\section{$P D E$ assay}

PDE activity was assayed under light- and GTPactivation conditions by the method of Thompson \& Appleman (1971). The standard incubation mixture contained $50 \mathrm{~mm}$-Tris $/ \mathrm{HCl}(\mathrm{pH} 7.4), 5 \mathrm{~mm}$ $\mathrm{MgCl}_{2}, 1 \mathrm{mM}$-cyclic GMP (Sigma), 1 mM-GTP, ${ }^{3} \mathrm{H}$ labelled cyclic GMP (New England Nuclear; 25000 c.p.m.; sp. radioactivity $10 \mathrm{Ci} / \mathrm{mmol}$ ) and $0.2 \mathrm{ml}$ of ROS preparation containing $1-10 \mu \mathrm{g}$ of protein $/ \mathrm{ml}$ in a final incubation mixture of $0.4 \mathrm{ml}$. Protein was determined by the procedue of Lowry et al. (1951).

\section{Native polyacrylamide-gel electrophoresis}

The $\mathrm{MgCl}_{2}$-free supernatant from the washed ROS membranes was electrophoresed into native polyacrylamide gels (Takemoto et al., 1980). The gels consisted of a Tris/glycine stacking system with a $4.5 \%$ stacking gel and a $10 \%$ resolving gel. Samples were electrophoresed at $2 \mathrm{~mA}$ per gel at $5^{\circ} \mathrm{C}$. Portions of the $\mathrm{MgCl}_{2}$-free supernatant were radioiodinated and run on parallel gels. Iodination did not result in loss of PDE activity. After electrophoresis, the gels containing non-radioactive fractions were sliced $(3 \mathrm{~mm})$ and eluted in $0.50 \mathrm{ml}$ of $50 \mathrm{~mm}-\mathrm{Tris} / \mathrm{HCl}(\mathrm{pH} 7.5)$ overnight at $4^{\circ} \mathrm{C}$. The PDE activity was assayed in each slice and the corresponding PDE-containing slice from the iodinated preparation was electrophoresed directly by SDS/PAg.e. (Laemmli, 1970). Protein bands were detected by autoradiography (Takemoto et al., 1981).

\section{Peptide mapping}

Approx. $10 \mu \mathrm{g}$ of protein was radioiodinated and resolved on $15 \%$ polyacrylamide gels by the method of Baehr et al. (1979). Molecular weights were calculated using human erythrocyte membrane proteins as markers (Fairbanks et al., 1971). After the completion of electrophoresis, the polyacrylamide gel was stained, destained and dried (Takemoto et al., 1981). The protein bands were visually detected by autoradiography and were excised from the gel and digested for $16 \mathrm{~h}$ at $37^{\circ} \mathrm{C}$ in $1 \mathrm{ml}$ of trypsin $(0.05 \mathrm{mg} / \mathrm{ml})$. After this digestion procedure, the samples were freeze-dried and subjected to two-dimensional peptide mapping as previously described (Takemoto et al., 1981).

\section{Results}

Fig. 1(a) illustrates the PDE activity profile of a bovine ROS supernatant resolved on a native polyacrylamide gel. An identical gel of radioiodinated ROS supernatant was run, and a parallel gel slice corresponding to the activity peak (slice no. 8) was electrophoresed on to an SDS gel. Autoradiography of this dried gel indicated that the PDE activity corresponded to a radioiodinated band of $85000 \mathrm{Da}$ (Fig. 1 b). Histochemical localization of bovine PDE on a native gel also indicated that the PDE activity migrated as a single peak (results not shown).

The presence of a single radioiodinated band of $85000 \mathrm{Da}$ is not in total agreement with the results of Baehr et al. (1979), who reported a doublet of 84000-88000 Da for bovine ROS PDE activity. The reason for this discrepancy is shown in Fig. 2, which demonstrates that the $85000-88000 \mathrm{Da}$ doublet becomes a single band of $85000 \mathrm{Da}$ after radioiodination.

The interspecies conservation of this polypeptide is shown in Fig. 3. ROS supernatants from all

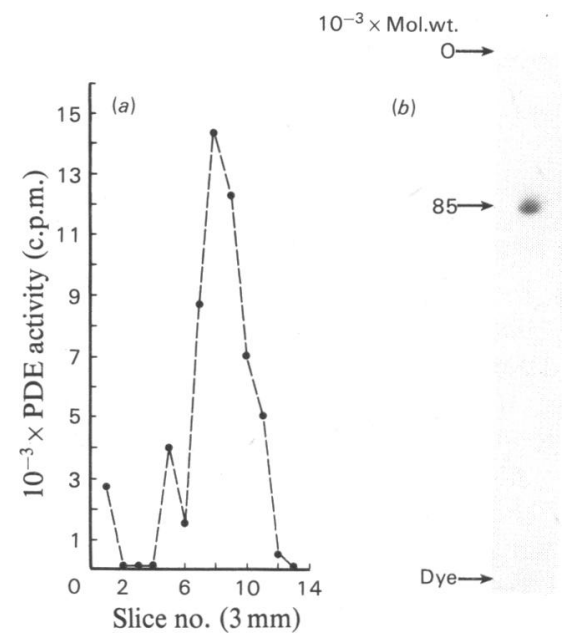

Fig. 1. Activity profile and SDS/PAg.e. analysis of ROS cyclic GMP PDE

(a) Approx. $200 \mu \mathrm{g}$ of $\mathrm{MgCl}_{2}$-free supernatant protein, prepared as described in the text, was iodinated with unlabelled $\mathrm{NaI}$ and chloramine-T. This preparation was resolved on a $10 \%$ native polyacrylamide-gel using $1 \mathrm{~mA} / \mathrm{gel}$ at $4^{\circ} \mathrm{C}$. Gels were sliced $(3 \mathrm{~mm})$, eluted overnight and then assayed for PDE activity as described in the text. (b) A parallel-run native gel of radioiodinated ROS-supernatant was also sliced and eluted as in $(a)$. The slice corresponding to maximum PDE activity in $(a)$ (no. 8) was run directly on to an SDS $/ 7.5 \%$ polyacrylamide gel and subsequently localized by autoradiography. 


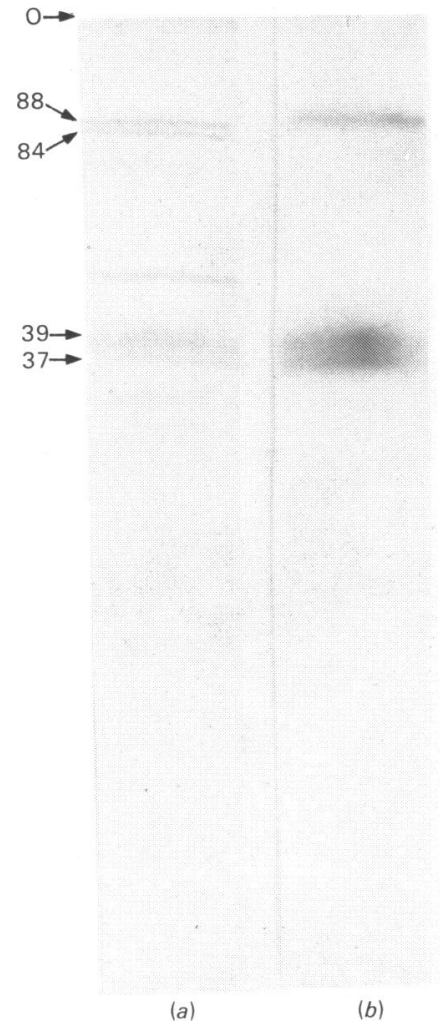

Fig. 2. Radiodination of bovine ROS supernatant Approx. $50 \mu \mathrm{g}$ of $\mathrm{MgCl}_{2}$-free supernatant, prepared from bovine ROS as described in the Materials and methods section, was resolved on $15 \%$ 'low bis' polyacrylamide gels as described by Baehr et al. (1979). The molecular weights $\left(\times 10^{-3}\right)$ are designated by arrows. (a) Coomassie Blue-stained gel of untreated ROS supernatant; (b) autoradiograph of ROS supernatant radioiodinated with $200 \mu \mathrm{Ci}$ of ${ }^{125} \mathrm{I}$ (Amersham; carrier-free).

four species contained a radioiodinated component that migrated at a molecular weight corresponding to approx. 85000 . In contrast with the other species, the frog proteins did not lose the doublet pattern after iodination (Fig. 3d)

Fig. 4 illustrates the results of two-dimensional tryptic peptide mapping of the $85000 \mathrm{Da}$ components of the dog, cow and the chicken and the lowermolecular-weight component $(85000 \mathrm{Da})$ of the frog. It is evident that although the proteins do not show identical maps they are related to each other. Arrows designate peptides that are common to the ROS PDEs from all four species.

A more accurate test of 'relatedness' may be made by co-mixing of tryptic peptides from proteins isolated from different species. For this purpose, mixing of the peptides from the frog and dog

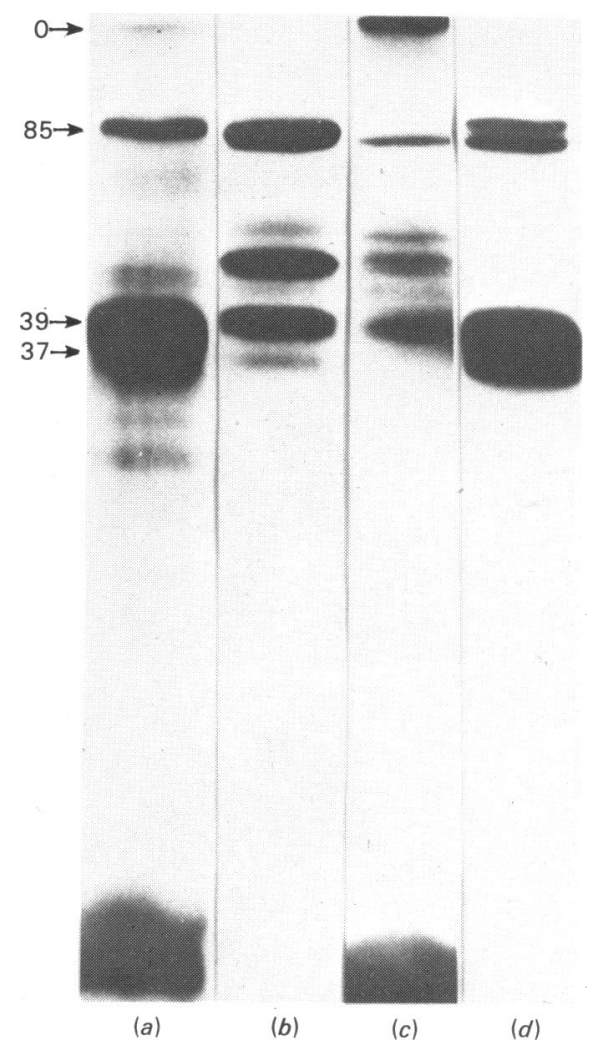

Fig. 3. Autoradiographs of the $\mathrm{MgCl}_{2}$-free supernatants from the ROS of different species

Approx. $10 \mu \mathrm{g}$ of protein was radioiodinated with $200 \mu \mathrm{Ci}$ of ${ }^{125} \mathrm{I}$, then resolved on $15 \%$ polyacrylamide gels by the method of Baehr et al. (1979). Arrows designate molecular weights $\left(\times 10^{-3}\right)$. (a) Dog; (b) cow; (c) chicken; (d) frog.

was done using equal counts of each sample. Fig. 5 illustrates that six peptides (arrows) co-migrated on the two-dimensional system. It should be emphasized that, owing to innate differences in iodination of proteins, a strict quantitative analysis of relative amounts of each peptide cannot be made using this technique. However, Figs. 4 and 5 demonstrate that this putative PDE has a significant degree of interspecies conservation.

\section{Discussion}

A biochemical characterization of the lightactivated PDE and its modulating components might help to elucidate the mechanism and role of this enzyme in the visual response. We have purified PDE from bovine ROSs. The radioiodinated $85000 \mathrm{Da}$ PDE component is found to be present and conserved in the four species examined. Miki 


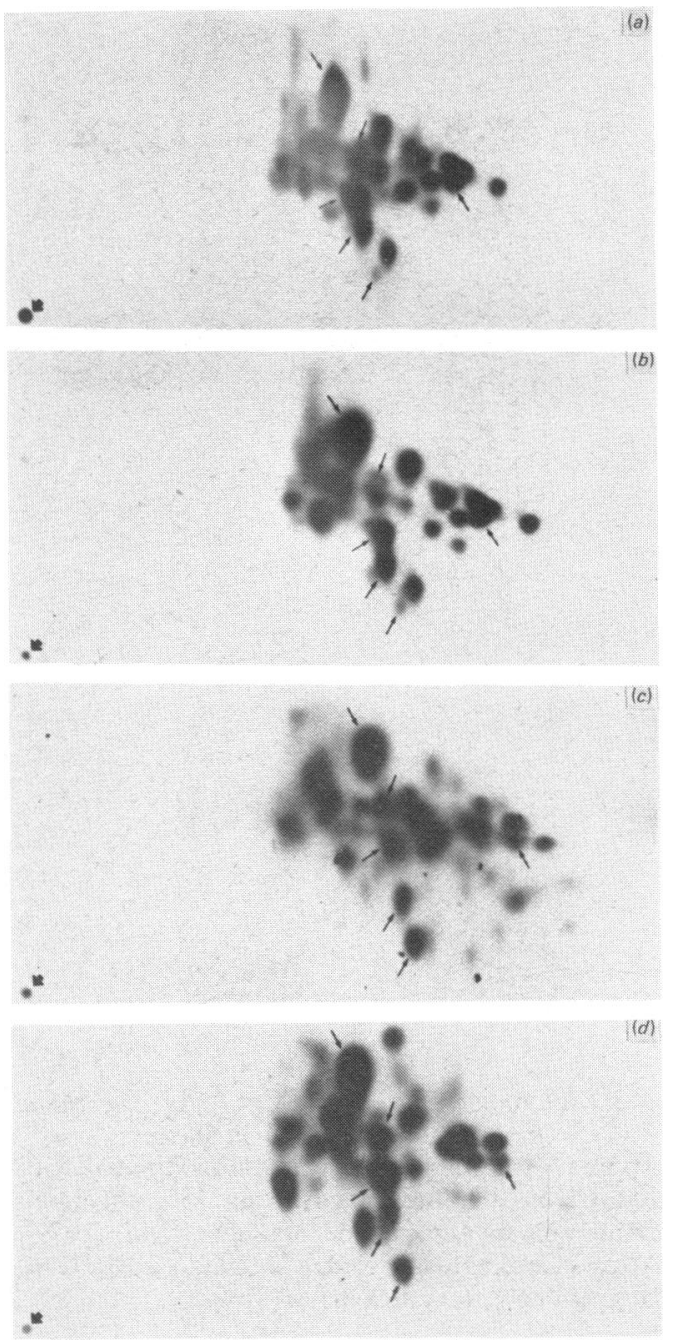

Fig. 4. Tryptic peptide maps of radioiodinated peptides from the $85000 \mathrm{Da}$ components isolated from different species

The proteins resolved in Fig. 3 were excised, digested and mapped as described in the Materials and methods section. First-dimensional electrophoresis was from left to right and second-dimensional chromatography was from bottom to top. Heavy arrows designate the sample origin. Light arrows designate radioiodinated peptides present in all species studied. ( $a$ ) Dog; (b) bovine; (c) chicken; (d) frog.

et al. (1975) isolated and characterized the ROS PDE from frog retina as a peripheral membrane protein present in a PDE/rhodopsin molar ratio of $1: 900$. The holoenzyme had a mol.wt. of 240000 , with subunits of 110000 and 120000 . In contrast, the ROS PDE from bovine retina has a mol.wt. of
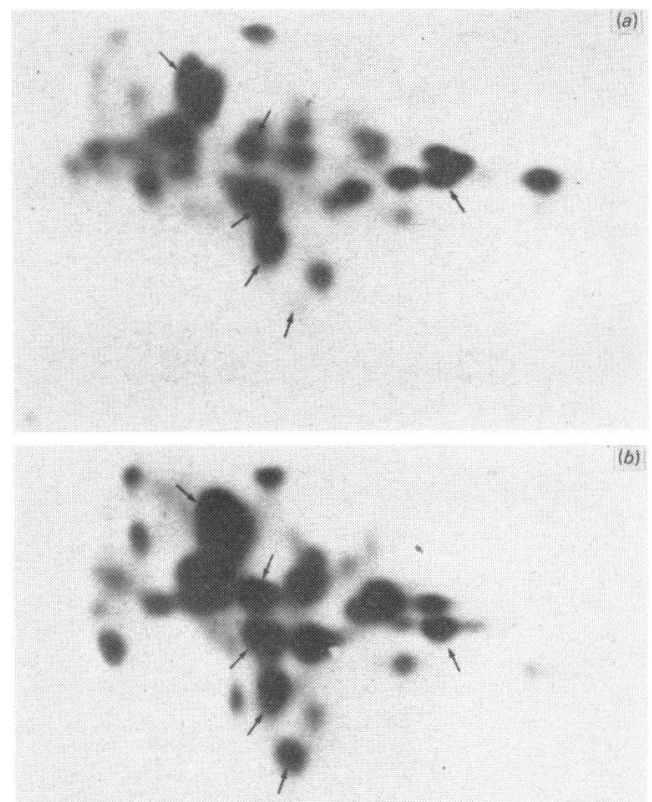

Fig. 5. Mixing of radioiodinated tryptic peptides from the $85000 \mathrm{Da}$ component of dog and frog ROS

Arrows designate the radioiodinated peptides common to both species. (a) $85000 \mathrm{Da}$ component from dog ROS; (b) $85000 \mathrm{Da}$ component from frog ROS; (c) a mixture of equal amounts of radioiodinated peptides (on the basis of radioactivity) from dog and frog.

170000 , with putative subunits of 84000 and 88000 , and is present in a higher ratio relative to rhodopsin $(1: 40)$ (Baehr et al., 1979). Coquil et al. (1975) have previously reported a higher molecular weight (105000) for partially purified ROS from bovine retina. This discrepancy may result from the use of an enzyme preparation by Coquil et al. (1975) that was eluted from non-denaturing polyacrylamide gels using non-ionic detergents. We have observed anomalous and inconsistent molecular weights using PDE preparations eluted in this manner. 
Although these discrepancies in the apparent molecular weights of PDE have not yet been reconciled, it is also possible that the frog PDE isolated by Miki et al. (1975) and the frog 85000 Da protein are the same component. Repetition of the isolation procedure of Miki et al. (1975), followed by resolution of proteins using the 'low bis' SDS/PAg.e. system of Laemmli (1970) as modified by Baehr et al. (1979), indicates that the major polypeptide component of this preparation migrates as a doublet of approx. $84000-88000 \mathrm{Da}$ (L. J. Takemoto \& D. J. Takemoto, unpublished work).

The protein doublet pattern of the ROS PDEs might reflect a slight modification that could be required for the interactions of subunits in an enzyme complex. Such a doublet was found in all of the species studied, including dog, cow, chicken and frog. Upon radioiodination, the doublet pattern was lost in all but the frog ROS preparation. The peptide maps of the 88000 and $84000 \mathrm{Da}$ PDE proteins are very closely related to each other (Takemoto et al., 1980). The fact that the $84000 \mathrm{Da}$ and $88000 \mathrm{Da}$ proteins are found in approximately equal and constant amounts argues against this being a random modification (Takemoto et al., 1980).

Tryptic peptide mapping has indicated that at least six of the major radioiodinated peptides of the putative PDE from all species studied have been conserved over approx. 200 million years of evolution. Such conserved peptides may be necessary in the catalytic and/or regulatory functions of this enzyme. Further studies using specific photoaffinity labels to ascertain the role of these peptides are required. It may be possible, using these techniques, to locate substrate-binding peptides in this PDE. This information, together with comparative studies of the PDE purified from animals with retina degeneration, will allow us to determine if alterations occur in this enzyme on a molecular level.
This work was supported by NIH grants EY02932 (L. J. T.), EY02651 (D. B. F.) and CA27500 (D. J. T.). D. J. T. is a Special Fellow of the Leukemia Society of America. This is contribution no. 81-317-j, Division of Biology, Kansas Agricultural Experiment Station.

\section{References}

Aguirre, G., Farber, D., Lolley, R., Fletcher, R. T. \& Chader, G. J. (1978) Science 201, 1133-1134

Baehr, 'W., Devlin, M. J. \& Applebury, M. L. (1979) J. Biol. Chem. 254, 1169-1177

Coquil, J. F., Virmaux, N., Mandel, P. \& Goridis, C. (1975) Biochim. Biophys. Acta 403, 425-437

Fairbanks, G., Steck, R. L. \& Wallach, D. F. (1971) Biochemistry 10, 2606-2617

Farber, D. B. \& Lolley, R. N. (1976) J. Cyclic Nucleotide Res. 2, 139-148

Farber, D. B. \& Lolley, R. N. (1977) J. Neurochem. 28, 1089-1095

Fung, B. K.-K., Hurley, J. B. \& Stryer, L. (1981) Proc. Natl. Acad. Sci. U.S.A. 78, 152-156

Goridis, C., Virmaux, N., Urban, P. F. \& Mandel, P. (1973) FEBS Lett. 30, 163-166

Laemmli, U. K. (1970) Nature (London) 227, 680-686

Lowry, O. H., Rosebrough, N. J., Farr, A. L. \& Randall, R. J. (1951) J. Biol. Chem. 193, 265-275

Miki, N., Keirns, J. J., Marcus, F. R., Freeman, J. \& Bitensky, M. W. (1973) Proc. Natl. Acad. Sci. U.S.A. 70, 3820-3824

Miki, N., Baraban, J. M., Keirns, J. J., Boyce, J. J. \& Bitensky, M. W. (1975) J. Biol. Chem. 250, 6320-6327

Papermaster, D. S. \& Dreyer, W. J. (1974) Biochemistry 13, 2438-2444

Pober, J. S. \& Bitensky, N. W. (1979) Adv. Cyclic Nucleotide Res. 11, 265-301

Takemoto, D. J., Kresie, R. \& Vaughn, D. (1980) Biochem. Biophys. Res. Commun. 93, 332-339

Takemoto, L. J., Hansen, J. S. \& Horwitz, J. (1981) Comp. Biochem. Physiol. 68B, 101-116

Thompson, W. J. \& Appleman, M. M. (1971) Biochemistry 10, 311-316

Woodruff, M. L., Bounds, D., Green, S. H., Morrisey, J. L. \& Shedlowsky, A. (1977) J. Gen. Physiol. 69, 667-679 